\title{
The 18S ribosomal RNA gene of a crustacean decapod Oedignathus inermis: a comparison with Artemia salina gene
}

\author{
Won Kim, Gi Sik Min and Sang Hee Kim \\ Department of Molecular Biology, College of Natural Sciences, Seoul National University, Seoul \\ 151-742, Korea
}

The nucleotide sequences of $18 \mathrm{~S}$ rRNA have been widely adopted for the construction of molecular phylogenies $(1,2)$. However, most studies used partial sequences without complete understanding of the sequence variability within a molecule of each species. There is only one species in crustaceans, Artemia salina, in which the complete nucleotide sequences of 18S rRNA gene were known (3). We were able to determine the complete 18S rDNA sequences of crustacean decapod Oedignathus inermis by means of PCR cloning and Taq sequencing.

PCR-primer sites are located at both ends of the molecule (TACCTGGTTGATCCTGCC, TAATGATCCTTCCGCAGGTT). A PCR-reaction was performed for 30 cycles (annealing $2^{\prime}, 52^{\circ} \mathrm{C}$; extension $3^{\prime}, 72^{\circ} \mathrm{C}$, denaturation $1^{\prime}, 94^{\circ} \mathrm{C}$ ). For blunt-ended ligation, the resulting fragments were modified as the blunt-end using T4 kinase and T4 polynucleotide polymerase by means of double Geneclean method (BIO 101). They were cloned in pUC 118 . Sequencing was conducted by Taqtrack kit (Promega Co.).

For examining sequence variability among crustaceans, we compared the nucleotide sequences of Oedignathus inermis (Order Decapoda, from present study) with those of Artemia salina [Order Branchiopoda. from Nelles et al. (3)]. We aligned the sequences of two species using FASTA program (4) (aligned sequences are not shown). The numbering system of nucleotide position found in the following text is that of Artemia salina without considering the insertion and/or deletion resulting from the alignment. The total length of the 18S rDNA of Oedignathus inermis is $1883 \mathrm{bp}$, which is longer than that of Artemia salina by 73 bases. The $\mathrm{G}+\mathrm{C}$ content is about $50 \%$ in each of two species. This value is slightly lower than those of vertebrates (5). The total numbers of different, identical, and null (insertion and/or deletion site) nucleotides between two species are 237, 1552 , and 115 respectively from alignment. The similarity between two species is $86.8 \%$ when the insertion and/or deletion sites were excluded. If we include the insertion and/or deletion sites and consider these sites as the unweighted nucleotide differences between two species, the similarity is $81.5 \%$. The ratio of transition/transversion is 1.03 in the present two species.
There are 18 insertion sites in Artemis salina and 26 in Oedignathus inermis. The number of nucleotide in each insertion site varies between' 1 and 18. The longest insertion is found at the position of 1700-1710 (18 bases) and the second most is at $1720-1730$ (13 bases). The 3 '-terminal region (position of 1739-1810) shows one nucleotide difference and one nucleotide insertion and/or deletion among total 72 nucleotides. Therefore this region is quite conservative. However. the present study shows that the largest conservative (identical) region locates at the position of $1266-1351$, and it is 86 bp long. The most variable region without considering the big insertion and/or deletion is at the position between 644-713. Within this region (among 70 bases), 27 nucleotide differences plus 4 insertion and/or deletion sites exist. This region corresponds to the V4 region between helices 19 and E19-1 of Nelles et al. (3), and confirms that this domain is the most variable region of the $18 \mathrm{~S}$ rRNA molecule (6).

\section{ACKNOWLEDGEMENTS}

We offer special thanks to Dr Hyune Mo Rho, of our department, for his patience while teaching us these techniques. This work was supported by research grants from the Ministry of Education of Korea (Institute for Molecular Biology and Genetics) and Korea Science and Engineering Foundation through the Research Center for Cell Differentiation (91-4-3).

\section{REFERENCES}

1. Field,K.G., Olsen,G.J., Lane,D.J., Giovannoni,S.J., Ghiselin,M.T., Ram,E.C., Pace,N.R. and Ram,R.A. (1988) Science 239, 748-753.

2. Turbeville,J.M., Field,K.G. and Ram,R.A. (1992) Mol. Biol. Evol. 9, 235-249.

3. Nelles,L., Fang,B.L., Volckaert,G., Vandenberghe,A. and De Wachter,R. (1984) Nucleic Acids Res. 12, 8749-8768.

4. Pearson,W.R. and Lipman,D.J. (1988) Proc. Natl. Acad. Sci. USA 85, $2444-2448$.

5. Torczynski,R.M., Bollon,A.P. and Fuke,M. (1983) Nucleic Acids Res. 11, 4879-4890.

6. Nickrent,D.L. and Sargent,M.L. (1991) Nucleic Acids Res. 19, $227-235$. 